Hemingway, M. A. (2001). Qualitative research in I-O psychology. The Industrial Organizational Psychologist, 38(3), 140-141.

Henwood, K. L., \& Pidgeon, N. F. (1992). Qualitative research and psychological theorising. British Journal of Psychology, 83, 97-112. doi:10.1111/j.2044-8295.1992.tb02426.x

Pratt, M. G., \& Bonaccio, S. (2016). Qualitative research in I-O psychology: Maps, myths, and moving forward. Industrial and Organizational Psychology: Perspectives on Science and Practice, 9(4), 693-715.

Qualitative guidelines: Criteria for evaluating papers using qualitative research methods. (n.d.). Retrieved from Journal of Occupational and Organizational Psychology website: http://onlinelibrary. wiley.com/journal/10.1111/(ISSN)2044-8325/homepage/qualitative_guidelines.htm

Smith, A. D., Madden, L. T., \& Ashmos Plowman, D. (2015). Readheaded no more: Tipping points in qualitative research in management. In C. E. Lance \& R. J. Vanderberg (Eds.), More statistical and methodological myths and urban legends (pp. 67-84). New York, NY: Routledge.

Wilhelmy, A., Kleinmann, M., König, C. J., Melchers, K. G., \& Truxillo, D. M. (2016). How and why do interviewers try to make impressions on applicants? A qualitative study. Journal of Applied Psychology, 101, 313-332. doi:10.1037/ap10000046

Willig, C. (2013). Introducing qualitative research in psychology (3rd ed.). Maidenhead, UK: Open University Press.

\title{
Additional Suggestions for Breaking Barriers Against Qualitative Research in I-O
}

\author{
David M. Fisher and Anupama Narayan \\ The University of Tulsa
}

In their focal article, Pratt and Bonaccio (2016) describe the potential value that qualitative research can bring to the field of industrial-organizational psychology (I-O) and also highlight several challenges (and myths) that must be overcome for this value to be fully realized. We agree with these authors, particularly with regard to the barriers that appear to stand in the way of fully integrating qualitative approaches with the science and practice of our field. Our purpose in this commentary is to build on the ideas of Pratt and Bonaccio by expanding the discussion of barriers against qualitative research. It is our view that further highlighting such barriers will illuminate several paths forward toward the increased adoption of qualitative methods, ideas, and approaches. More specifically, we focus on the following three barriers: (a) categorical thinking, (b) the uncertainty of that which is unknown, and (c) an overemphasis on generalizability in psychological research. We discuss each of these in turn below. Tulsa.

David M. Fisher and Anupama Narayan, Department of Psychology, The University of

Authorship is listed alphabetically by last name. Both authors contributed equally.

Correspondence concerning this article should be addressed to David M. Fisher, Department of Psychology, The University of Tulsa, 800 South Tucker Drive, Tulsa, OK 74104. E-mail: david-fisher@utulsa.edu 
First, we as human beings have an impressive but also limited capacity to process information. To augment this limited capacity and correspondingly handle the massive amounts of information with which we are typically inundated, we often engage in the mental practice of chunking, whereby we create proverbial silos or buckets of related information that can be linked, stored, and recalled more efficiently (Miller, 1956/1994). In effect, we employ mental categories as a heuristic mechanism for understanding the world, where such categories are additionally influenced by training, education, and cultural ideology. Ultimately, this culturally imbued process of mental categorization has the potential to manifest in perceptions of the world as characterized by strict either/or distinctions. This same process appears to be in operation with qualitative research, which tends to be conceptualized as being in an entirely separate category from quantitative research and in many ways also antithetical to the goals of quantitative methods. However, as is often true, a closer look reveals that things are not so black and white after all. Rather, qualitative research aims to answer research questions, does so by examining phenomena of interest, involves the collection of data (typically in the form of written words), and is concerned with the credibility of conclusions derived from the data-all of which are also hallmarks of quantitative research. This is not meant to disregard the real differences that exist between qualitative and quantitative approaches, but in many cases, the differences are likely smaller than they seem and might better be viewed as differences of degree rather than a strict categorical distinction. Accordingly, we encourage researchers to view qualitative methods not as a separate category but instead as a set of tools (like quantitative methods) that can be fruitfully used to further advance the primary aim of I-O research, namely, to achieve a better understanding of people at work.

Second, to the extent that qualitative research is viewed as a separate and distinct category, this has the potential to evoke the natural human inclination to be wary of that which is different, unknown, or contrary to the norm. In other words, considering the greater emphasis given to quantitative research in most I-O programs, there is likely to be a general preference for what is known and thus comfortable (i.e., quantitative methods) and a corresponding tendency to avoid what is perceived as unfamiliar and thus uncertain (i.e., qualitative methods). This is consistent with the general idea that people tend to favor options for which they have more explicit information (Kahneman \& Tversky, 1996) and further reflected in the view of qualitative research as a "redheaded stepchild" (Eby, Hurst, \& Butts, 2009). To overcome this particular barrier, we believe it is critically important to acknowledge that many of the primary methods of qualitative research already have a strong foothold in the practice of I-O. Specifically, job analysis efforts frequently involve interviews with subject matter experts, 
observation of job incumbents, or the elicitation of narratives in cognitive task analysis. In this sense, these job analysis efforts are often used in a manner akin to inductively generating an understanding of the job in question, much like qualitative research is used for inductive theory development. Thus, simply acknowledging that some of the focal topics already taught in I-O programs bear a striking resemblance to qualitative methods in turn may make qualitative research seem a little less foreign and unapproachable. Furthermore, this suggests a potentially viable conduit through which qualitative methods might be more explicitly incorporated in I-O program curricula.

Third, in the field of psychology, much emphasis is placed on generating theories and empirical findings that are generalizable. Although consideration of generalizability is obviously important-for example when considering the degree to which findings from a contrived laboratory setting transfer to real world situations-it is similarly important to acknowledge that an overemphasis on generalizability is potentially problematic. Namely, an unfortunate consequence of overvaluing generalizability (especially in field research) is that specific aspects of a study's sample or setting may be overlooked or discussed in generic terms so as to obfuscate any unique features that might challenge generalizability (Johns, 2006). This is certainly not to say that considering generalizability is bad but rather to say that an overemphasis on generalizability tends to place all the unique and potentially important aspects of a study's setting in the category of noise to be controlled or otherwise explained away. Yet, the unique aspects and features of particular settings can often have a profound influence, such that understanding the features may be as important as (if not more important than) whether the findings directly generalize to other situations (cf. Bell, Fisher, Brown, \& Mann, in press). As a result, although qualitative research has the potential to further shed light on the many unique features that impinge on organizational life, such research is less likely to be accepted if journal reviewers, editors, and quantitative researchers continue to have a knee-jerk reaction to the apparent lack of generalizability associated with qualitative approaches, even if broad generalizability is not the intention of the study. Therefore, we encourage all of the various constituents of I-O research to continue emphasizing the importance of generalizability, but in due moderation and with a critical eye.

Some barriers such as physical walls are hard to miss. Other barrierssuch as implicit assumptions, social norms, and those that derive from the limited information processing capacities of the human mind-are much harder to identify, let alone overcome. In the latter case, a fundamental prerequisite to overcoming such barriers is first acknowledging that they exist and then making inroads toward breaking them down. It is our hope that the 
discussion of barriers above (albeit brief) is a positive step in this direction for qualitative research in the field of I-O.

\title{
References
}

Bell, S. T., Fisher, D. M., Brown, S. G., \& Mann, K. E. (in press). An approach for conducting actionable research with extreme teams. Journal of Management. Advance online publication. doi:10.1177/0149206316653805

Eby, L. T., Hurst, C. S., \& Butts, M. M. (2009). Qualitative research: The redheaded stepchild in organizational and social science research? In C. E. Lance \& R. J. Vandenberg (Eds.), Statistical and methodological myths and urban legends: Doctrine, verity and fable in the organizational and social sciences (pp. 219-246). New York, NY: Routledge.

Johns, G. (2006). The essential impact of context on organizational behavior. Academy of Management Review, 31, 386-408. doi:10.5465/AMR.2006.20208687

Kahneman, D., \& Tversky, A. (1996). On the reality of cognitive illusions. Psychological Review, 103, 582-591. doi:10.1037/0033-295X.103.3.582

Miller, G. A. (1994). The magical number seven, plus or minus two: Some limits on our capacity for processing information. Psychological Review, 101, 343-352. doi:10.1037/0033-295X.101.2.343 (Reprinted from Psychological Review, 1956, 63, 81-97)

Pratt, M. G., \& Bonaccio, S. (2016). Qualitative research in I-O psychology: Maps, myths, and moving forward. Industrial and Organizational Psychology: Perspectives on Science and Practice, 9(4), 693-715.

\section{Understanding Deep, Socially Embedded Human Motivations and Aspirations for Work From Whole Person and Interdisciplinary Perspectives}

\author{
Teresa J. Rothausen \\ University of St. Thomas-Minnesota
}

As someone trained exclusively as a quantitative researcher, who recently became a semi-autodidactic qualitative researcher (see Rothausen, Henderson, Arnold, \& Malshe, in press; "semi" in part because I am still learning and in part because my coauthors have taught me), I would like to extend the argument made by Pratt and Bonaccio (2016) for increasing qualitative research in the domains of industrial-organizational psychology (IOP), organizational behavior (OB), and human resources (HR), and I would also add industrial relations (IR), which was my doctoral field of study and "where workers went" within business and management studies as HR became more aligned with organizational interests (see Lefkowitz, 2016, from this journal). I extend their argument by deepening one of their reasons,

Teresa J. Rothausen, Department of Management, Opus College of Business, University of St. Thomas-Minnesota.

Correspondence concerning this article should be addressed to Teresa J. Rothausen, Department of Management, Opus College of Business, University of St. Thomas-Minnesota, 1000 LaSalle Avenue-TMH 443, Minneapolis, MN 55403. E-mail: tjrothausen@stthomas.edu 